\title{
KOMMUNIKASIE MET PASIëNTE -- DIE EFFEK VAN VERBALE EN NIE-VERBALE KOMMUNIKASIE OP BEWUSTELOSE PASIëNTE
}

\section{Margot Weich}

\section{Opsomming}

Kommunikasie, hetsy verbaal of nie-verbaal, is ' $n$ vaardigheid wat deesdae baie verwaarloas word weens verskeie redes, waarvan te min tyd en gebrekkige belangslelling in ander persane. maar enkeles is.

Aangesien dit maeilik is om verbale en nie-verbale kommunikasie te skei, is die effek van beide vorme, ongeag of hulle tesaam of apart voorgekom het, bestudetr. Empiriese gegewens dui daarop dal bewustelose pasiënte baie sensitief is vir die aard van kommunikasie. 'n Pasiënt se intrakraniale druk mag styg of daal na gelang van die gesprek wat gevoer word.

Musiek en aanraking veroorsaak soortgelyke effekte op die pasiën. Die invloed van kommunikasie is egter nie slegs tot inurakraniale drukveranderinge beperk nie. Ook die simpatiese en parasimpatiese senuweestelsel, met gevolglike invloed op hartspoed, word beinvloed 'n Boodskap van aanvaarding of verwerping kan eweneens oorgedra ward. Kommunikasie is dus essensieel en behoort baie meer aandag te geniet as wat wel die geval is.

\section{Absract}

Communication, both verbal and non-verbal, is a greatly neglected skill at present. Two reasons given for this state of affairs are lack of time and lack of interest in others.

Since it is difficult to separate verbal and non-verbal communication, the effects of both types were studied, whether or not they occurred simultaneously. Empirical evidence shows that unconscious patients are highty sensitive to the nature of communication, and that their intracranial pressures rise or fall concomitant in the way in which a conversation is being conducted within hearing dilance. Music and touch seem to have similar consequences.

The influence of communication is, however, not confined to inuracranial pressure changes. The sympathetic and parasympathetic nervous systems are also affected, with associating changes in the heart rate.

Messages of acceptance or rejection may be conveyed verbally or non-verbally. Communication with patients appears to be decisive, and should therefore warrant far greater attention than it receives at present.

\section{INLEIDING}

In die hoogs tegnologiese omgewing van vandag word tyd as 'n baie belangrike kommoditeit gereken. Almal $\mathbf{k l a}$ dat hulle nie meer tyd het om dit te doen wat hulle graag sou wou doen nie. 'n Aspek wat deesdae ook sterk op die voorgrond gedryf word is die mannekrag tekort en die krisis warin die gesondheidsdienste hulself bevind. Gesien in dié lig sal die volgende stelling waarskynlik heelwat teenstand uitlok, naamlik: Indien daar meer en beter met pasiênte gekommunikeer word, sal dit hul herstel bevorder en hul verblyf in die intensiewe sorgeenhede verkort. In die algemeen sal menige verpleegkundige waarskynlik van mening wees dat sy haar eerder met belangriker take moet besig hou, soos interpretering van spesifieke parameters en aandag aan al die monitors waaraan 'n pasiënt gekoppel is. Dit is so dat verpleegkundiges geskool word om hulle nie besig te hou met allerhande onbenullighede soos gesels nie, maar eerder icts daadwerkliks vir die pasiënt moet

doen. Botha (1990) is van mening dat dit wel die moeite werd is om die pasiênt deeglik in te lig aangaande die rede vir sy opname, sy siekte en sy behandelingsprotokol aangesien dit sy stres aansienlik verlig.

Kommunikasie met die naasbestaandes van die pasiênt en dié tussen die lede van die multiprofessionele span sal nie hier bespreek word nie. Dit is egter 'n area wat ook aandag verdien soos bevind deur Elliott \& Smith (1985.111). Die versorging van die pasiënt en die kommunikasie met die naasbestaandes van die pasiënt sal egter meer effektief verloop as die lede van die multiprofessionele span uit een mond sou praat.

\section{REDES VIR GEBREKKIGE KOMMUNIKASIE}

Mense het nie meer tyd om met mekaar te kommunikeer nie. Wanneer daar bymekaar gekom word, is die respons op die vraag 'Hoe gaan dit?' dikwels so in die verbygaan: 'Goed net besig!' sonder om tot stilstand te kom. Hiermee word eintlik te kenne gegee: 'Moenie my nou pla nie, ek het nie nou tyd nie'. Dieselfde geneigdheid word die intensiewe sorgeenhede binnegedra. Wanneer 'n pasiënt dit waag om te vra dat iets verduidelik moet word, is die reaksie dikwels dat daar later verduidelik sal word aangesien daar eers ' $n$ bepaalde belangrike taak is wat dringend aandag verg. As gevolg van die geweldige nuusdekking wat die gesondheidsdienste die afgelope tyd geniet, is die publiek terdee bewus van die personeel rekort en swyg dus byvoorbaat sodat hulle nie die personeel onnodig pla nie. Gevolglik neem doeltreffende kommunikasie ook geleidelik af.

\section{AFBAKENING VAN DIE STUDIE}

Verbale en nie-verbale kommunikasie is bestudeer. Die rede is tweeledig. In die eerste plek word verbale en nie-verbale kommunikasie met bewustelose pasiënte dikwcls verwaarloos, weens die wanopvatting dat totale afstomping van ervaring van eksterne stimulasie plaasvind. In die tweede plek was dit moeilik om die twee soorte kommunikasie te skei aangesien die 
gesinslede van die pasiènte dikwels nie-verbaal, en selde slegs verbaal, met hulle gekommunikeer het. Dit is ook so dat dit uiters moeilik is om met 'n persoon te gesels wat nie verbaal kan reageer nie. Daar bestaan egter vandag voldoende bewyse dat kommunikasie, hetsy verbaal of nie-verbaal, wel 'n baie groot invloed op die pasiênt se siektebelewing en herstel uitoefen. In gesprekke met pasiënte wat hoofbeserings gehad het en vir een tot drie maande in 'n koma was, slaag hulle dikwels daarin om baie akkuraat gebeure gedurende die periode van bewussynsverlies weer te gee. Die pasiënt wat vir die eerste keer kennis maak met 'n intensiewe sorgeenheid, ervaar vrees en onsekerheid as niemand vir hom verduidelik wat die betekenis van al die aktiwiteite is nie. Hoe dikwels word daar nie bloedmonsters of röntgenogramme van die pasiënte geneem sonder dat hulle ooit ingelig word waarom dit gedoen word of wat die uitslag is nie?

Willemse (1989:180) het bevind dat juis gebrekkige kommunikasie as een van die grootste leemtes deur pasiênte in intensiewe sorgeenhede ervaar is. Die pasiënte wou graag weet hoe hulle vorder, wat die uitslag van die ondersoeke was, hetsy positief of negatief, en wat die doel van sekere behandelingsmaatrëels was (1989:130). 'n Aspek wat ook in die studie na vore gekom het, was dat die pasiente dikwels van die personeel se nie-verbale gedrag afleidings omtrent hulself gemaak het. Waar die personeel soms onderlinge geskille gehad het, het dit die pasiènte ontstel en het hulle hul dit as persoonlike belewenis ervaar (1989:149-153,157).

\section{BESPREKING}

Empiriese gegewens is in 'n opname studie van bewustelose pasiënte ingewin (Hugo,1989). Die effek van kommunikasie op die intrakraniale druk is duidelik aangedui. By ongeveer $26 \%$ van die pasiënte het die druk gedurende kommunikasie gedaal. Die gemiddelde dalings van sommige pasiènte oor die 72-uur periode waartydens hulle geobserveer is, was $2,71,0,5$, 1,00, 0,25, 4,14 en 4,25 mm Hg onderskeidelik. Die pasiênte se intrakraniale druk het minder gestyg wanneer die verpleegkundige tydens verpleegsorghandelinge verbaal met hulle gekommunikeer het, as wanneer sy aksies uitgevoer het sonder om met hulle te kommunikeer. Hierdie bevindinge korreleer met dié van groepe soos Walleck (1986), Snyder (1983)en Mitchell \& Mauss (1978). Die wyse waarop daar met die pasiênt gekommunikeer word is eweneens belangrik. Mitchell \& Mauss (1978: 4-10) het bevind dat die tipe gesprek wat gevoer word ook 'n invloed op die pasiènt se intrakraniale druk (IKD) uitoefen. Indien 'n emosioneel stimulerende gesprek binne hoorafstand van die pasiěnt gevoer word, is drukstygings waargeneem. Hierdie gesprekke het gehandel oor die toestand van die pasient, sy prognose, sy pyn en beperkings. Hulle vermeld egter nie die kwaliteit en kwantiteit van die drukstygings nie. Snyder (1983:277) het 'n gemiddelde drukstyging van $9,03 \mathrm{mmHg}$ waargeneem wanneer 'n gesprek oor die pasiènt gehandel het. 'n Gemiddelde daling van 2,4 $\mathrm{mmHg}$ het voorgekom wanneer die pasiènt direk aangespreek is. In gevalle waar daar voor die besering 'n swak verhouding tussen die spreker en die pasient was, het die pasiènt ook groter IKD-stygings getoon. Roekelose opmerkings in die teenwoordigheid van bewustelose pasiente moet te alle tye vermy word, aangesien daar nie met sekerheid gese kan word hoe die breinbeseerde pasient hierdie inligting sal interpreteer nie. Dalings in die IKD is waargeneem wanneer daar op 'n rustige en terapeutiese wyse met pasiënte gesels is.

Walleck (1986) het in 'n soortgelyke ondersoek daarin geslaag om pasiente se intrakraniale druk te laat daal deur op 'n rustige wyse met hulle te kommunikeer. Hoewel sy nie die kwaliteit of kwantiteit van die daling meld nie, word die effek gestaaf deur ander navorsers se bevindinge. Pollack en Goldstein (1981:732) is van mening dat gesprekvoering deur gesinslede voordelig vir bewustelose pasiente is. Hulle bevind dat intrakraniale druk vanaf vlakke bo $15 \mathrm{mmHg}$ tot onder $10 \mathrm{mmHg}$ daal, veral wanneer ouditêre en gevoelsstimulasie gekombineer word. Johnson, Omery en Nikas (1989:56) is van mening dat die invloed van verbale kommunikasie op intrakraniale druk moontlik afhanklik is van die bewussynsvlak. Dit is egter 'n kuns om voortdurend te kommunikeer met 'n diep bewustelose persoon wat geen sigbare response toon nie.

Sisson (1990:373-378) het daarin geslaag om 'n duidelike respons op ouditêre stimuli by diep komateuse pasiënte aan te dui. Al vyf die hoofbeseerde pasiènte in haar studie het 'n Glasgow-komaskaaltelling van 6 of minder gehad wat op 'n ernstige toestand dui. Sy het 'n deurlopende EEG op die pasiênte uitgevoer terwyl ouditêre stimuli toegepas is. Die daaropvolgende evaluering van hierdie pasiènte het ' $n$ betekenisvolle verbetering in hulle toestand aangetoon. Die Glasgowkomaskaaltellings het by twee van die pasiènte sodanig verbeter dat hulle toestand as matig gestremd beskryf is. Die ander drie pasiènte het ook 'n verbetering getoon, maar was ses weke na die primêre breinbesering steeds ernstig gestremd. Hoewel dit 'n loodsstudie en slegs kontekstueel van aard was en gevolglik nie veralgemeenbaar is nie, dui dit aan dat pasiènte wat in 'n diep koma verkeer wel op ouditêre stimuli reageer.

Op dieselfde wyse het musiek of gesprekke op band ook 'n duidelike positiewe of negatiewe invloed op die IKD uitgecefen, afhangende of dit vir die pasiënt aanvaarbaar was of nie. Hoewel dit slegs by een pasiënt duidelik waargeneem is, het die invloed van musiek duidelik in die studie van Hugo (1989) na vore gekom. Die betrokke pasiënt was lid van 'n koorgroep en is tydens hul toer beseer. Die koor het vir hom die werke wat hulle die aand sou uitvoer op band opgeneem en gespeel. By die grootste deel van die koorwerke het die pasiènt se intrakraniale druk gedaal, maar by sekere dele het dit merkbaar gestyg. Dit mag wees dat dié betrokke dele of tegnies moeiliker was of die pasiènt het nie van daardie snitte gehou nie Hoewel hierdie bevinding nie gestaaf word nie, mag daar ander faktore wees wat ook 'n betekenisvolle rol kan speel, soos die beseringsarea en breinhemisfeerdominansie. Guzzetta (1989:609) het bevind dat musiek 'n betekenisvolle vermindering in stres by pasiënte met miokardiale infarksies teweeg gebring het. Hoewel hierdie persone se bewussynsvlak geensins benadeel was nie, kon 'n duidelike fisiologiese respons op die ouditêre stimuli aangedui word. Dit is daarom belangrik dat die keuse van musiek sodanig sal wees dat dit die pasiènt se gesondheidstoestand sal bevorder en nie benadeel nie.

'n Verdere aspek wat nie deur enige van die navorsers bespreek is nie is die regs- of linkshandigheid van die pasiënte. By die pas afgelope kritieke sorgkongres het Jones (1991) vermeld dat serebrale bloedvloei deur die tipe ouditêre stimulus en die bepaalde breinhemisfeerdominansie beïnvloed word. Dit mag daartoe aanleiding gee dat afhangende van die lokalisasie van die breinbesering en die pasiènt se breinhemisfeerdominansie, sekere ouditêre stimuli die serebrale bloedvloei kan laat toeneem of afneem na gelang van die geval, met gevolglike toename of afname in intrakraniale druk. 'n Faktor wat ook in gedagte gehou moet word is in welke mate die bloedbreinskans deur die siektetoestand of onderliggende patologie benadeel is. Indien die bloedbreinskans beskadig is en meer proteien deurgelaat word sal dit tot breinswelling aanleiding gee en dus die intrakraniale druk laat styg. Dit is volgens hierdie gegewens duidelik dat al die fakiore wat ' $n$ rol speel by serebrale bloedvloei, en die evaluering van die effek van kommunikasie of musiek as terapeutiese tussentrede, nie in berekening gebring is nie Hierdie aspekte benodig gevolglik noukeurige navorsing

In soortgelyke studies is die invloed van aanraking ook bestudeer. Walleck (1986) bevind dat sy ' $n$ betekenisvolle daling in IKD kon bewerkstellig deur die pasiènt se wang of hand te streel. Hierdeur kon kosbare tyd "gekoop" word totdat daadwerklike terapeutiese optrede beplan kon word. Weiss (1979:76-80) het 'n breedvoerige studie oor die taal van aanraking gedoen. Sy meld dat die duur van aanraking die persoon bewus maak van sy liggaamsgrense en -besonderhede. Die kwaliteit van aanraking is eweneens belangrik. Die wyse waarop 'n persoon aangeraak word stuur 'n besondere boodskap uit. Dit is daarom belangrik dat verpleegkundiges 'n rustige, bemoedigende wyse van aanraking sal bemeester en dit gereeld toepas. Estabrooks (1989:392-401) het bevind dat meer aandag aan aanraking as deel van 'n bepaalde verplegingstrategie in intensiewe sorgeenhede gegee behoort te word. In haar studie merk sy verder op dat daar in gedagte 
gehou moet word dat alle pasiënte aanraking nie altyd positief ervaar nie. Aanraking as sodanig behoort gevolglik ook bestudeer te word en die wyse waarop verskeie persone aanraking ervaar behoort aandag te geniet. Weiss (1990: 479) is egter van mening dat hoewel aanraking as sodanig nie nadelige effekte vir die pasiènt het nie die terapeutiese waarde daarvan nie summier aanvaar kan word nie. Sy meld dat daar aanvaar kan word dat pasiënte wat nie 'n afkeur in aanraking het nie, die aanraking wel stres kan verminder wat terapeuties kan wees.

Die fisiologiese effek van aanraking is ook al deur verskeie navorsers ondersoek (Schoenhofer,1989; Johnson, Omery \& Nikas,1989). Volgens Schoenhofer (1989:146) is liefdevolle aanraking essensieël vir die normale groei en ontwikkeling van babas en jong kinders. Sy is van mening dat kinders en volwassenes met afwykings in hulle gesondheidstoestand selfs 'n groter mate van aanraking benodig as onder normale omstandighede. In die kritieke sorg omgewing mag anraking egter beide voordelige as nadelige gevolge hè. Die behoefte aan aanraking in die kritieke sorgeenheid mag baie groter as in die gewone saal wees, maar aangesien die pasiënt hemodinamies onstabiel en moontlik baie meer prikkelbaar is, is die risiko van ongewenste effekte groter.

In die kritieke sorgeenheid word pasiënte blootgestel aan 'n hoogs tegnologiese omgewing wat 'n bedreiging vir hul psigologiese welsyn inhou. Pasiente het probleme om hul eie identiteit en 'n goeie selfkonsep te handhaaf wat aanleiding mag gee tot depersonalisasie, sensoriese deprivasie (of corlading) en disoriëntasie. Holloway (1984) is van mening dat sosiale isol asie 'n realiteit in die kritieke sorg omgewing is. Veelvuldige omgewingstimuli van onpersoonlike aard is die reël en weinig sosiale interaksie vind plaas. Hoewel die pasiěnt blootgestel word aan veelvuldige aanraking, is die aanraking eerder van instrumentele aard wat die gevoel van sosiale isolasie vererger.

Weiss (1986:495-505) het 'n onderskeid tussen verskillende soorte aanraking getref. Die navorser meld dat prosedure-aanraking stres kan genereer, terwyl versorgingsaanraking "caregiving-touch" stres kan verlig. Stres aktiveer die simpatiese senuweestelsel wat daartoe aanleiding gee dat katesjolamien vrygestel word met gevolglike tagikardie en disritmes. Ontspannende maatrëels, daarenteen, aktiveer die parasimpatiese senuweestelsel wat tot 'n daling in hartspoed lei en die drempel vir ventrikulêre fibrillasie verhoog. Dit lyk asof die pasiënte se harte selfs hiperreaktief tot die geringste aanraking is. Die effek van aanraking is egter afhanklik van die aard van die impulsgeleiding deur die sentrale senuweestelsel (SSS). Die respons op impulsgeleiding is afhanklik van die invloed op die outonome senuweestelsel (OSS) en of die simpatiese of parasimpatiese bane van die OSS geaktiveer word. McCorkle (1974:125-132) is van mening dat aanraking en gesprekvoering met ernstige siek pasiente van groot waarde is om die gevoel dat daar vir hul omgegee word en dat hulle aanvaar word ten spyte van hul siekte, te verseker. Lynch et al. (1977:188-191) is van mening dat aanraking in die kritieke sorgeenheid selfs van groter belang is. Hulle het veranderinge in die hartspoed van bewustelose pasiënte gevind wat spierverslappers ontvang het en meganies geventileer is. Die verpleegpersoneel het ' $n$ afname in polsspoed waargeneem deur bloot die pasiènt terapeuties aan te raak terwyl hulle brongiale toilet uitgevoer het. Hierdie respons is by vyf opvolgstudies ook aangedui en die navorsers was van mening dat dit ' $n$ ongekondisioneerde fisiologiese refleks was.

In die geval van bewustelose pasiënte is enige faktor wat tot verhoogde breinaktiwiteit bydra, 'n risiko om intrakraniale druk te laat styg, wat op sy beurt weer nadelig vir die pasiènt kan wees. Faktore wat onder andere tot verhoogde breinaktiwiteit, en gevolglike verhoogde breinmetabolisme, aanleiding gee is stresgenererende toestande, pyn, ongemak, vrees of emosionele toestande. Die probleem waarmee geworstel word is egter of sensoriese deprivasie die stres sal laat toeneem en of aanraking 'n gevoel van veiligheid en geborgenheid teweeg sal bring. Een van die toestande wat as gevolg van sensoriese deprivasie of - oorlading kan ontstaan is intensiewe sorg-psigose wat twee tot drie dae na opname in 'n intensiewe sorgeenheid mag ontwikkel. Hoewel verskeie faktore vir die toestand verantwoordelik kan wees, is omgewingsfaktore veroorsaak deur slaapdeprivasie, geraas, helder beligting in die vier-en-twintig uur, vreemde omgewing, sensoriese oorbelading, afhanklikheid, immobilisasie, moniteringsapparaat en gebrekkige kommunikasie van die belangrikste faktore wat moontlik reggestel kan word (Easton \& MacKenzie, 1988:231). Aangesien elke persoon uniek is, nie net ten opsigte van sy persoonlike ruimte nie, maat ook ten opsigte van sy siektetoestand, moet die kommunikasie met die pasiènt individueel beplan en aangepas word. Schoenhofer (1989:153) kom tot die gevolgtrekking dat die ervaring, van beide die pasiënt en die verpleegkundige, ten opsigte van aanraking nog intensiewe bestudering benodig aangesien die motivering, effek en behoefte nog nie duidelik uitgespel is nie. Die navorser stel 'n kwalitatiewe fenomenologiese benadering voor.

Aanraking moet egter met groot omsigtigheid gebruik word, aangesien elke persoon oor 'n bepaalde persoonlike ruimte beskik wat gerespekteer behoort te word. King, soos aangehaal deur Ingham (1989:68) is van mening dat aanraking ' $n$ metode is om inligting te bekom en ook om inligting te kommunikeer, en dat dit veral van waarde is by pasiënte wat nie verbaal kan kommunikeer nie, soos persone met afasie of pasiënte wat geïntubeer is.
Aanraking as 'n uitdrukkingsvorm is effektief, veral wanneer woorde ontbreek. Pasiènte wat in isolasie versorg word, het by uitstek 'n behoefte aan die een of ander vorm van aanraking. Persone wat probleme ondervind om vrede met 'n veranderde liggaamsbeeld te maak of om een of ander vorm van fisieke gestremdheid te verwerk, sal baat daarby as hulle aanvaarding beleef wat voortspruit uit die aanraking van die verpleegkundige of die behandelende geneesheer. Volgens Goodykoontz (1979:4-17) is anraking ' $n$ vorm van nie-verbale kommunikasie wat, wanneer met sorg en die nodige sensitiwiteit gebruik, 'n boodskap van "caring" oordra en dit dra 'n gevoel van welsyn oor wat die pasiënt se herstel positief kan beïnvloed. Ingham (1989:69) meld dat: "human beings communicate through everything they do as well as everything they say, and to cease to communicate is to cease to exist." McCorkle (1974:125) is van mening dat: "through touch, nurses may indicate concerm, interest and caring for patients, and with the seriously ill patient physical contact can aid in establishing rapport in a short time." Heidt (1981:32-37) het in haar studie oor terapeutiese aanraking 'n betekenisvolle afname in post toetsstres gerapporteer by die proefpersone wat wel aangeraak was voor die aflegging van die posttoets.

Simon, soos aangehaal deur Ingham beweer: "It has been a well established medical fact for over $\mathbf{2 0 0 0}$ years that a competent, calm, understanding, empathic human being can be a reliable and effective tranquiliser and the one with the fewest undesirable physiological side effects." (1989:65).

\section{SLOT}

Wanneer hierdie fasette van verbale en nie-verbale kommunikasie in oënskou geneem word, behoort verpleegkundiges daarop te let hoe, waar en wanneer hulle met hul pasiènte kommunikeer aangesien dit wel 'n betekenisvolle invloed op bewustelose pasiènte se welsyn kan uitoefen soos geillustreer deur voorafgaande fisiologiese barometers.

\section{BRONNELYS}

BOTHA A 1990: Cardiac rehabilitation from a nurse's point of view. Referaat gelewer by die 12 de Kritieke Sorg Kongres. Bloemfontein.

EASTON C. AND MACKENZIE F. 1988 : Sensory-perceptual alterations: Delirium in the intensive care unit. Heart \& Lung. Vol. 17:229-237.

ELLIOTT J AND SMITH DR 1985: Meeting family needs following severe head injury: A multidisciplinary approach. Journal of neurosurgical nursing. Vol 17:111-113

ESTABROOKS CA. 1989: Touch: A nursing strategy in the intensive care unit. Heart \& Lung. VOL18:392-401. 
GOODYKOONTZ L. 1979: Touch:attitudes and practice. Nursing forum. Vol 18(1):4-17.

GUZETTA CE. 1989: Effects of relaxation and music therapy on patients in a coronary care unit with presumptive acute myocardial infarction. Heart \& Lung. Vol 18:609-616.

HEIDT P. 1981: Effect of therapeutic touch on axiety level of hospitalized patients. Nursing Research. Vol 30:32-37.

HOLLOWAY NM. 1984: Nursing the critically ill adult. 2nd edition. Menlo Park, California: Addison-Wesley.

HUGO MJ 1989: Die effek van verpleegsorghandelinge op die intrakraniale druk van die hoofbeseerde pasiënt. D Soc Sc-proefskrif. Universiteit van die Oranje-Vrystaat. Ongepubliseerde werk.

HUGO MJ 1991: Empiriese waarneming en persoonlike ondervinding in plaaslike akademiese en ander hospitale.

INGHAM A.1989: A review of the literature relating to touch and its use in intensive care. Intensive Care Nursing. Vol 5:65-75.

JOHNSON SM, OMERY A AND NIKAS D 1989: Effects of conversation on intracranial pressure in comatose patients. Heart \& Lung. Vol 18:56-63.
JONES, G., 1991: Cerebral function. Referaat gelewer by Kritieke Sorgkongres, Durban, 3-7 Junie.

LYNCH J,THOMAS SA AND PASKEWITZ DA, et al. 1977: Human contact and cardiac arrhythmia in a coronary care unit. Psychosomatic Medicine. Vol 39:188-191)

MCCORKLE R. 1974: The effects of touch on seriously ill patients. Nursing Research. Vol 23:125-132.

MITCHELL PH AND MAUSS NK. 1978 Relations of patient-nurse activity to intracranial pressure variations: a pilot study. Nursing Research. Vol 27:4-10.

POLLACK L AND GOLDSTEIN G. 1981: Lowering of intracranial pressure in Reye's syndrome by sensory stimulation (letter). New England Journal of Medicine. No 304:732.

SCHOENHOFER SO. 1989: Affectional touch in critical care nursing: A descriptive study. Heart \& Lung. Vol 18:146-154.

SISSON R. 1990: Effects of auditory stimuli on comatose patients with head injury. Heart \& Lung. Vol 19:373-378.

SNYDER M. 1983: Relation of nursing activities to increases in intracraial pressure.
Journal of Advanced Nursing. Vol 8:273-279.

WALLECK C. 1986: Increased intracranial pressure. Referaat gelewer by die 2 de Internasionale Intensiewe Sorgkongres in Den Haag.

WEISS SJ 1979: The language of touch. Nursing Research. Vol 28:76-80.

WEISS SJ. 1986: Psychophysiologic effects of caregiver touch on the incidence of cardiac dysrhythmia. Heart \& Lung. Vol. 15:495-505.

WEISS SJ. 1990: Effects of differential touch on nervous system arousal of patients recovering from cardiac disease. Heart \& Lung. Vol. 19:474-480.

WILLEMSE AM 1989: 'n Ondersoek na die pasiènt se belewenis van sy verblyf in 'n intensiewesorgeenheid. M Soc Sc-skripsie. Universiteit van die Oranje-Vrystaat. Ongepubliseerde werk. 